evaporated to get rid of the gypsum, and afterwards further evaporated in vacuum pans, and run into barrels ready for crystallisation.

MATERIAL changes are officially reported from the Bay of Talcahuano, in Chile, which was surveyed by Captain Fitzroy. The commander of the Chilean war steamer Ancud now reports that the water throughout the entire extent of the bay has increased from two to two-and-a-half fathoms. This represents great geological change. The rock Fraile, in the Gulf of Arauco, represented on Fitzroy's chart as a sunken rock, is now, however, a small island united to the mainland, opposite to the western bank of the river Tubul, and has rather the shape of a quadrangular pyramid.

THE Times of India states that the coal-beds discovered in Bellary are excellent in quality and abundant in quantity. Great anxiety is felt for Dr. Oldham, who said he would eat all the coal found in the Madras Presidency, for the doctor is a man of honour.

From a considerable number of observations on the temperatures of the two sides of the body, Mr. Blake draws the following conclusions, which are recorded in the Medical Times and Gazette of October 8, 1870:-r. That the temperature of the sides of the trunk under usual circumstances, i.e. in health and at rest in a temperate climate, is equal. 2. That under certain conditions the temperature of the left side of the trunk may exceed that of the right. 3. That that excess during exertion in a cool atmosphere averages half a degree $F$. 4. That that excess reaches its maximum of about one degree $F$. during exertion under a powerful sun.

\section{THE GEOGRAPHICAL DISTRIBUTION OF} $D E E R^{*}$

I $\mathrm{N}$ his excellent "Geographische Mittheilungen," Dr. 1 Petermann has lately given us several zoo-geographical articles, as we may call them-such as those of Dr. Finsch on the distribution of Parrots, and of Freiherr von Heuglin on the Bird-fauna of North-eastern Africa. Both of these memoirs are the products of the highest authorities on the subjects to which they respectively relate, and deserve our warmest commendation. We cannot, however, say so much as to the merit of the paper upon the Geographical Distribution of Deer, which appears in a recent number of Dr. Petermann's journal. The authors of this memoir, which, if properly treated, is on a subject of very great interest, have, we fear, commenced to indulge in "generals" before having sufficiently got up their "particulars." In the first part of their essay they point out the present distribution of the different genera and species of Cervidee over the world's surface, and endeavour to show how they have descended from a common ancestral form. This form they imagine must have been the Moschida, upon the ground that in order to obtain a deer with horns we must pre-suppose the existence of a deer without horns, and the Moschida answer this definition. Unfortunately, however, the authors have not yet discovered that their so-called group Moschide is composed of two forms of animal life that have very little to do with one another. It has been shown most conclusively by the researches of $\mathrm{M}$. Alphonse Milne-Edwardst in Paris, and Prof. Flower in our own country, that the Cherrotains (Tragulus and Hyomoschus), one of the constituents of

* "Die Geographische Verbreit ung der Hirsche mit bezug auf die Geschichte der Polar-länder." Von Gustav Jaeger und Emil Bessels. (Petermann's Geographische Mittheilungen, 1870.)

$\dagger$ " Recherches Anatomiqueset Palæontologiques sur la famille des Chevrotains," Paris, 1864

I "Notes on the Visceral Anatomy of Hyomoschus aquetocus." Proc. Zool. Soc., 1867 . the Moschida of MM. Jaeger and Bessels, constitute a family per se, quite distinct from the rest of the ruminants, and connecting them with the pigs, and consequently quite distinct from the musk-deer (Moschus). In the same way our authors base certain arguments upon the fact of all the typical deer being spotted in the immature state. But, as Dr. Jaeger at least-having been, if we are not misinformed, custos of a zoological garden-ought to know, this is not quite the case, all the Rusine deer having their young spotless. Again, arguments are founded upon Cervus pudu of Chili living in the Cordilleras, and the other allied species with simple unbranched horns in the plains of South America. But exactly the contrary is the case. Cervus pudu is from the low maritime coast of Chili, ana one, if not more, of the so-called "Subulones" (C. rufius) lives high in the Andes of Venezuela and New Granada. From these and other similar instances of erroneous statements which it would be easy to point out, it is, in fact, quite obvious that the authors of this essay have no very special acquaintance with the group upon the distribution of which they treat. We leave it to naturalists to decide whether, under these circumstances, the results arrived at are worthy of much attention. Their theory seems to be that the deer-family reached the New World by an Arctic continent which formerly connected northern Europe with eastern America, and which Dr. Jaeger, in a former paper, has proposed to call "Arctis." There are, however, if we are not mistaken, equally good grounds for believing that the numerous, undoubtedly Old-world forms in North America reached it by immigration from North-western Asia.

\section{HENDERSON'S PATENT STEEL PROCESS}

TWO articles written by $\mathrm{Mr}$. W. Mattieu Williams, called "Papers on Iron and Steel-A Costly and Vexatious Fallacy," were published a short time since in NATURE. These papers are considered in this country to be the clearest and ablest that have ever appeared on this subject, setting forth the reason why all efforts heretofore made to produce steel from English cast-iron by partial decarbonisation have failed; that all manipulations have been directed to removing as much as possible the impurities contained in pig iron by oxidation. He was not aware that new agents have been used, combined with oxygen, and that patents had been granted therefor in England, Nos. 318, I,05I, A.D. I870 (which were not then published) for combining fluorine with oxygen, and fluorine combined with titanic acid, or with titanium and oxygen.

The new patent process for the production of steel by the partial decarbonisation of cast-iron consists in the combined use of fluorspar or other fluorides and titanic acid, applied to cast-iron at the melting temperatures, preferably in reverberatory furnaces. Fluorine is given off from the fluorspar, and is a more powerful agent for the removal of silicon than oxygen, and removes it almost entirely from the cast-iron before the reactions with the carbon begin; the phosphorus and sulphur are next acted upon and removed in the order they are named by means of the combined action of fluorine and titanic acid or fluorine, titanium, and oxygen, and lastly the carbon is removed. The fluorine is derived from fluorspar combined with iron ores containing titanic acid in such wise as ensures simultaneous action of the fluorine, titanium, and oxygen upon the cast-iron; and by reason of the affinities of these substances for silicon, phosphorus, sulphur, manganese, arsenic and carbon, these substances are taken from the iron in the form of vapour and slag, leaving the purified metal in the condition to be hammered or rolled as merchantable steel.

English pig-iron may be made direct into steel by the new process; and with the large class of irons smelted from hæmatites and specular ores with good fuel, pure 